\title{
Anti-predator behaviour of Rhinella major (Müller and Hellmich 1936), with insights into the Rhinella granulosa group
}

\author{
Fillipe Pedroso-Santos ${ }^{1}$, Carlos Eduardo Costa-Campos ${ }^{2}$ \\ 1 Universidade Federal do Amapá, Programa de Pós-Graduação em Biodiversidade Tropical, 68903-419, Macapá, Amapá, Brazil \\ 2 Laboratório de Herpetologia, Departamento de Ciências Biológicas e da Saúde, Universidade Federal do Amapá, 68903-419, Macapá, \\ Amapá, Brazil \\ http://zoobank.org/7844B6E1-2BE0-4B75-9057-DD84590B2625
}

Corresponding author: Fillipe Pedroso-Santos (fillipepedrosodossantos@gmail.com)

Academic editor: Eva Ringler • Received 4 April 2021 • Accepted 26 August 2021 • Published 23 September 2021

\begin{abstract}
In anurans, the different types of anti-predator behaviour have been documented in isolation, but some species have shown synergistic strategies in different situations. The display of these types of behaviour may be related to the types of predators in the habitat, which boost defensive responses in their prey. However, most reports are mostly opportunistic and punctual observations, not systematic. Here, we report the occurrence of anti-predator behaviour in the toad Rhinella major (Müller and Hellmich 1936) (Amphibia, Anura, Bufonidae) in the face of different handling modes. Probably the disturbance caused by handling had elicited a predator deterrence response in the individual, causing it to rapidly exhibit such behaviour. These conditions are discussed along with an overview of anti-predator behaviour in species of the R. granulosa group and we re-interpreted these strategies for two species in the group.
\end{abstract}

\section{Key Words}

anuran behaviour, Bufonidae, ethogram, gape-limited predator, handling

\section{Introduction}

Several species of anuran amphibians have evolved different types of anti-predator behaviour synergistically with phylogenetic and morphological traits, for example, related to body size, colour patterns and toxin production. This selection is driven by a variety of vertebrate and invertebrate predators that prey on amphibians (Duellman and Trueb 1994, Toledo et al. 2007). Generally, many species of anurans have evolved escape behaviour, such as jumping away, to avoid predation. However, species incapable of adopting rapid escape strategies have evolved other anti-predator behaviour, such as death feigning, stretching of limbs or body inflation (Toledo et al. 2011, Ferreira et al. 2019). Amongst these types of behaviour, death feigning is the most widespread amongst animals (e.g. Miyatake et al. 2004, 2009, Cassill et al. 2008, Ferreira et al. 2019). In anurans, this behaviour is characterised by loosening of fore- and hind limbs, usually with the dorsum on the substrate, playing dead (Humphreys and Ruxton 2018, Ferreira et al. 2019). The stretching of limbs is characterised as a full or partial extension of the fore- or hind limbs and the body inflation is characterised by the act of fully inflating the lungs (Ferreira et al. 2019).

The different types of anti-predator behaviour have been documented in isolation (see Mângia and Santana 2013), but some species have shown synergistic strategies in different situations (e.g. Escobar-Lasso and González-Duran 2012). However, some authors argue that anti-predator behaviour can only be considered as 'defensive strategies' when they are, in fact, effective in reducing or stopping predator attacks (e.g. Brodie Jr et al. 1991, Humphreys 
and Ruxton 2018, Ferreira et al. 2019). Most reports, however, are opportunistic and punctual observations, not systematic and contain speculative interpretations.

Currently, the defensive types of behaviour of Rhinella major (Müller and Hellmich 1936) have been reported, informally, from observations of two predatory events. First, the lung inflation (referred to as "puffing up the body") and secretory products of skin glands (adhesive) were reported by Pedroso-Santos et al. 2020. Additionally, Pedroso-Santos et al. (2018) observed the same secretion of gland products which led to the interruption of a predation attempt by regurgitation by the anuran predator (Leptodactylus aff. podicipinus). Here, we describe new observations of the anti-predator behaviour of Rhinella major, including death feigning, stretching of limbs and body inflation. We provide a re-interpretation of these types of behaviour for $R$. granulosa and R. pygmaea, as well as new insights into anti-predator defences of this group.

\section{Methods}

The Rhinella granulosa group is comprised of small and medium-sized morphologically distinct toads, characterised by heavily ossified skulls, keratinised cephalic crests and keratinised tubercles of varying sizes on the body (Narvaes and Rodrigues 2009). These toads are distributed from Central America (Panama) to southern South America (Argentina and Uruguay) (Frost 2021, Pereyra et al. 2021). Recently, Pereyra et al. (2021) recognised 13 species for the monophyletic group: Rhinella granulosa (Spix 1824), R. pygmaea (Myers and Carvalho 1952), $R$. bergi (Céspedez 2000), R. major (Müller and Hellmich 1936), R. mirandaribeiroi (Gallardo 1965), R. azarai (Gallardo 1965), R. nattereri (Bokermann 1967), R. dorbignyi (Duméril and Bribon 1841) [including R. fernandezae (Gallardo 1957) as new synonymy], $R$. merianae (Gallardo 1965), R. humboldti (Gallardo 1965), R. centralis Narvaes and Rodrigues 2009, R. bernardoi Sanabria et al. 2010 and $R$. beebei (Gallardo 1965).

$R$. major is a terrestrial species of moderate size (Snout-vent length $35.8-72.8 \mathrm{~mm}$ in adult males and $33.9-81.1 \mathrm{~mm}$ in adult females), distributed in the Chaco Region of Argentina, Paraguay and Bolivia and in open areas along the Rivers Madeira, Beni, Amazonas, Tapajos and Xingu in Brazil (Narvaes and Rodrigues 2009, Frost 2021). In the State of Amapá, the species is abundant in urban and disturbed areas (Pedroso-Santos, pers. obs.).

We conducted field observations at night from $1900 \mathrm{~h}$ to 2200 h, between August 2018 and July 2019, in urban areas in the Municipalities of Macapá $\left(0.0083^{\circ} \mathrm{S}, 51.0953^{\circ} \mathrm{W}\right.$, datum WGS84) and Santana $\left(0.03589^{\circ} \mathrm{S}, 51.16077^{\circ} \mathrm{W}\right.$, datum WGS84), in Amapá State, Brazil. The field observations were performed once a week by a researcher, totalling a sampling effort of 144 hours/man. The areas sampled are characterised by abandoned properties and lots, with open environments and temporary lentic water bodies and an equatorial climate with annual precipitation of $2850 \mathrm{~mm}$ and average annual temperatures ranging from $27.6-38.0{ }^{\circ} \mathrm{C}$
(Alvares et al. 2013). All field observations were made in 2 $\mathrm{m}^{2}$ plots spaced each $10 \mathrm{~m}$ apart to avoid the recapturing of individuals already sampled on the same night.

Types of anti-predator behaviour of Rhinella major were observed during cautious approach and during and after the manual capture close to the substrate (the toads were lifted approximately $20 \mathrm{~cm}$ from the substrate). One of us (FPS) approached the frogs and, after 5 min of observations, handled them simulating a predator attack. Each individual was handled only once in different and random ways, with handling lasting approximately $10 \mathrm{~min}$. The individuals were subjected to only one of the following modes of handling: grabbing them on the dorsum/dorsolateral, by the inguinal and cloacal regions, by the head and by the limbs. For each mode of handling, a repetition of 10 times of use was considered. Combinations of handling types and the selection of their use were not considered in this study to avoid confounding toad responses. Individuals who exhibited a posture resembling a dead organism, with their ventral region turned upwards on the hand or when placed on the substrate and with their limbs held close to body or relaxed were recorded as death-feigning. Likewise, individuals who inflated themselves were recorded as body inflation and those who displayed full or partial extension of the fore- or hind limbs were recorded as stretching of limbs. All terms used to define these types of behaviour followed Ferreira et al. (2019). After our field observations, all individuals who displayed these types of behaviour were photographed, measured and released at the original place of encounter.

This study was conducted with all due ethical procedures and permission from the Brazilian wildlife regulatory service (SISBIO \#48102).

\section{Results}

Of 65 sampled individuals, the percentage of toads displaying potential anti-predator behaviour was $67.70 \%(n=44)$. The most frequently observed behaviour for $R$. major that appeared in isolation was either death feigning $(55.88 \%, n$ $=19$, Fig. 1A) or body inflation $(44.11 \%, n=15$, Fig. 1C). Stretching of limbs was observed only once and synergistically with body inflation (Fig. 1D). Death feigning and body inflation behaviour was observed in both juveniles and adults. Ten individuals (22.72\%) displayed synergistic strategies: body inflation with death feigning $(90.0 \%$, $n=9$, Fig. 1B) and body inflation with stretching of limbs $(10.0 \%, n=1)$. When handled, individuals who synergistically displayed body inflation with death feigning, immediately inflated their bodies and remained immobile in a position resembling a dead organism with their ventral region turned upwards on the hand, with their limbs held close to the body and maintained that position while it was in the observer's hand. Once released, toads remained with the dorsum on the substrate with the lungs still inflated for about 30 seconds. The only individual which synergistically displayed body inflation with stretching of limbs immediately inflated its body when released on the substrate and soon after fully extended its fore- and hind limbs. 


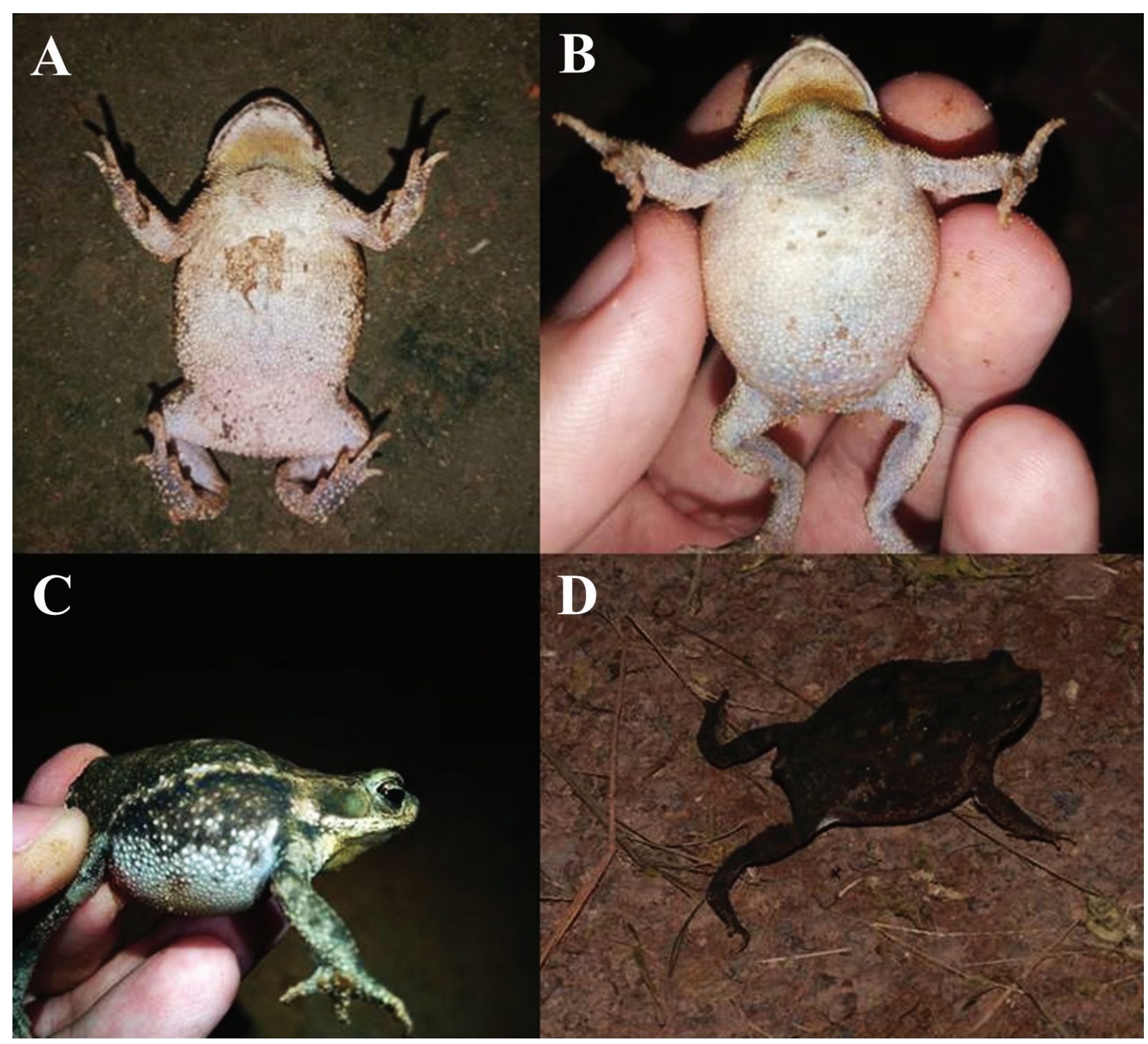

Figure 1. Anti-predator behaviour of Rhinella major. A. Death feigning behaviour; B. Death feigning involving body inflation as synergistic behaviour; C. Body inflation behaviour; D. Body inflation involving stretching of limbs as synergistic behaviour.

As for the way of handling individuals with the kind of behaviour displayed by them, only the handling by the limbs did not present any defensive response $(100.0 \%$, $n=15)$. Individuals handled by the head displayed only death feigning behaviour $(50.0 \%, n=3)$; three individuals $(50.0 \%)$ did not display defensive responses. Those handled by the inguinal and cloacal regions displayed only body inflation behaviour $(66.66 \%, n=4)$; two individuals (33.34\%) did not display defensive responses. We observed that defensive responses were more frequent and variable when individuals were handled by the dorsum/dorsolateral region; only one individual did not display any defensive responses (see Fig. 2).

\section{Discussion}

To our knowledge, the data presented here demonstrate the first formal record of anti-predator behaviour in $R$. major.
Yet, we do not know if these types of behaviour are effective against its natural predators. However, we expect this species to employ the same behaviour already recorded for the $R$. granulosa group due to morphological and habitat similarities. The death feigning behaviour in synergy observed in R. major is similar to the report of $R$. pygmaea (referred to as "death feigning in isolation" by Figueiredo-de-Andrade and Silveira 2018), in which the authors mention that the individual had slightly inflated lungs. The same considerations occur with our observations of stretching of limbs in synergy in $R$. major to the reports in $R$. granulosa and R. pygmaea (referred to as "stiff-legged in isolation" by Mângia and Santana 2013 and Figueiredo-de-Andrade and Silveira 2018, respectively). In all cases, body inflation behaviour occurred in synergy with death feigning and the stretching of limbs, but the authors claim that they did not detect this synergistic behaviour. According to Ferreira et al. (2019), death feigning and limb stretching behaviour in isolation does not require minimal 


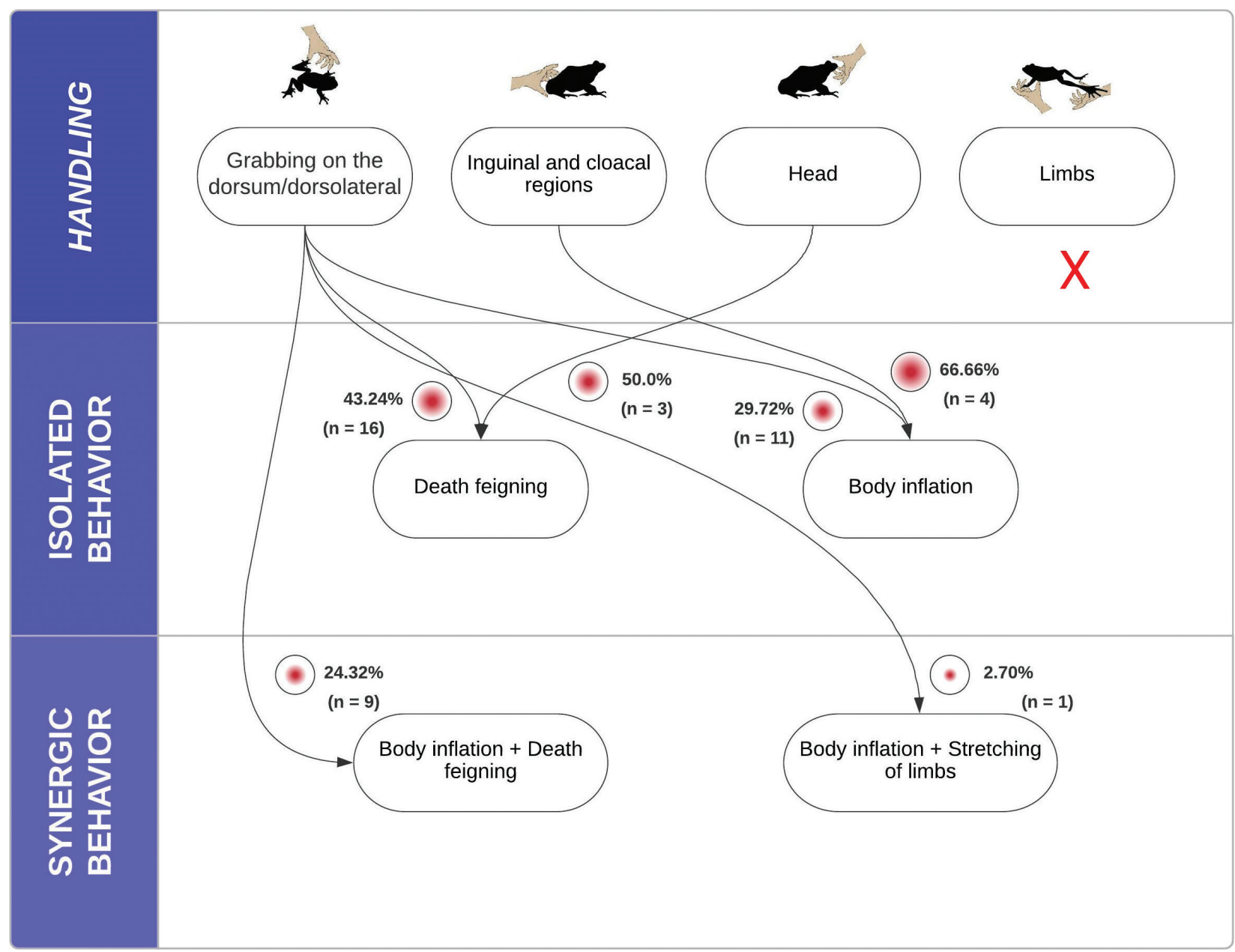

Figure 2. Ethogram of anti-predator behaviour displayed by Rhinella major. The circles represent, in gradient, the frequency of the displayed behaviour. The $\mathrm{X}$ mark represents the absence of defensive responses.

inflation of the lungs. Therefore, we suggested that stretching of limbs in $R$. major, $R$. pygmaea and $R$. granulosa involves body inflation as synergistic behaviour. In fact, species of the genus Rhinella are considered relatively heavy and the total stretching of its legs in isolation would be difficult and, therefore, the inflation of the lungs could generate an eccentric contraction on the legs due to the increase in body size. In addition, our observations consider that death feigning may be displayed in isolation or in synergy with body inflation for the same species. On the other hand, although the body inflation behaviour appears to be a synergistic tactic occurring alongside other strategies described for the species, it is also employed in isolation, as observed in our study for R. major and for other reports in $R$. granulosa (Fonseca et al. 2018) and $R$. mirandaribeiroi (Valencia-Zuleta et al. 2020).

In the genus Rhinella Fitzinger, 1826, death feigning is not formally described to occur in synergy with body inflation (see Toledo et al. 2010, 2011, Ferreira et al. 2019; Table 1). Thus, our data indicate the first records of these conditions for the genus, specifically in the $R$. granulosa group. These types of behaviour are responsible for warning predators to keep away and avoid direct contact with the prey (Ferreira et al. 2019), because (i) several predators, different from scavenger animals, require vital signs of the prey to employ foraging behaviour and (ii) body inflation, in addition to intimidating the potential predator, also makes subjugation difficult. In the case of synergy, when two or more defensive strategies are used, it is likely to increase the chances of escape and survival (Toledo et al. 2011). However, this condition does not apply to all predators, be-

Table 1. Anti-predator defences of species in the Rhinella granulosa group. * Re-interpreted behaviour.

\begin{tabular}{l|c|c}
\hline Species & Anti-predator defences & Reference \\
\hline \multirow{2}{*}{$\begin{array}{l}\text { Rhinella } \\
\text { major }\end{array}$} & Skin secretion & Pedroso-Santos et al. (2018) \\
\cline { 2 - 3 } & $\begin{array}{c}\text { Skin secretion in synergy with Body } \\
\text { inflation }\end{array}$ & Pedroso-Santos et al. (2020) \\
\cline { 2 - 3 } & Death feigning & This study \\
\cline { 2 - 3 } & Body inflation & This study \\
\cline { 2 - 3 } & $\begin{array}{c}\text { Death feigning in synergy with Body } \\
\text { inflation }\end{array}$ & This study \\
\cline { 2 - 3 } & Body inflation in synergy with \\
Rhinella & Stretching of limbs & This study \\
\hline Rhinella & Body inflation in synergy with \\
pygmaea & Stretching of limbs* & Mângia and Santana (2013) \\
\cline { 2 - 3 } & Beath feigning in synergy with Body & Figueiredo-de-Andrade and \\
& inflation* & Silveira (2018) \\
\cline { 2 - 3 } & Body inflation in synergy with & Figueiredo-de-Andrade and \\
& Stretching of limbs* & Silveira (2018) \\
\hline \multirow{2}{*}{$\begin{array}{l}\text { Rhinella } \\
\text { humboldti }\end{array}$} & $\begin{array}{c}\text { Skin secretion in synergy with Body } \\
\text { inflation }\end{array}$ & $\begin{array}{c}\text { Vargas-Salinas and Aponte- } \\
\text { Gutierrez (2013) }\end{array}$ \\
\hline
\end{tabular}


cause their morphological, physiological and behavioural characteristics are conditioning factors in survival and not of the prey after the attack. For example, Pedroso-Santos et al. (2020) observed the production of skin secretion (adhesive) in synergy with body inflation (referred to as "puffing up the body") in an unusual predatory event on a juvenile R. major by a spider of the genus Thaumasia Perty, 1883, in which the applied anti-predator types of behaviour were not effective in preventing its death. Likewise, Pedroso-Santos et al. (2018) noticed the same adhesive secretion in $R$. $m a$ jor when a frog of the species Leptodactylus aff. podicipinus tried to subdue it. In this case, although the juvenile $R$. major died, the defensive behaviour employed by $R$. major caused the predator to regurgitate. In the case of prey surviving an attack, Fonseca et al. (2018) reported the efficiency of body inflation behaviour in stopping the subjugation of $R$. granulosa by the toad $R$. jimi and Vargas-Salinas and Aponte-Gutierrez (2013) noticed the body inflation in synergy with skin secretion in $R$. humboldti as a cause of the regurgitation in the snake Leptodeira septentrionalis (Kennicott 1859); in both cases, the authors observed injuries from attacks by their predators, in which $R$. granulosa died $24 \mathrm{~h}$ after the attack, while $R$. humboldti survived.

Although body inflation behaviour is a recognised defensive strategy of anurans against predation attempts by snakes (Wells 2007, Toledo et al. 2011), it has also been effective against predatory frogs (see Fonseca et al. 2018, Pedroso-Santos et al. 2018). Moreover, stretching of limbs has been documented for leaf-litter frogs, because the species that display this anti-predator behaviour try to mimic fallen leaves to confuse visually-orientated predators (Sazima 1978). However, this behaviour was observed, although in synergy, for $R$. major, $R$. granulosa and $R$. pygmaea, all of which are considered forest-dwelling species. Therefore, we suggest that body inflation is a widespread defensive behaviour amongst species of the genus Rhinella and its effectiveness may be related to vertebrate predators. The limb stretching behaviour, displayed in $R$. major, $R$. granulosa and $R$. pygmaea, needs to be investigated further to understand whether this behaviour is displayed in isolation or in synergy with types of behaviour other than body inflation. Further, we reinforce the hypotheses of Mângia and Santana (2013), which pointed out that the stretching of limbs could be a plesiomorphic character in Neobratrachia (sensu Pyron and Wiens 2011) and this behaviour is likely to be display by arboreal hylids and centrolenids, as well as in leptodactylids, but additional data are needed to evaluate the diversification of this behaviour within the clade. Additional observations of potentially isolated or synergistic types of behaviour are needed for $R$. bergi, $R$. azarai, $R$. nattereri, $R$. dorbignyi, $R$. fernandezae, $R$. merianae, $R$. centralis, $R$. bernardoi and $R$. beebei, which so far remain unknown.

Regarding the modes of handling used in our study with the kind of behaviour displayed by the individuals, it is most likely that the disturbance caused by handling had elicited a predator deterrence response in the individual, causing it to rapidly exhibit such behaviour. Therefore, this condition would be better related to the learning of avoidance of detection and subjugation in the condition as prey. Thus, we sug- gest that body inflation behaviour, displayed when grasped by the inguinal and cloacal regions, may have been a developed mechanism for individuals of $R$. major for defence against a gape-limited predators, such as snakes, because such behaviour would make the process of subjugation or swallowing difficult. Even though some vertebrates (e.g. snakes and lizards) tend to prey on toads through headfirst ingestion, a low frequency of this mode of ingestion can be recorded for some lineages (see Mori 2006), resorting to catching prey through the bite by the cloacal region, dorsum and dorsolateral. Such condition was observed by Vargas-Salinas and Aponte-Gutierrez (2013), in which they recorded the body inflation behaviour as the cause of regurgitation in Leptodeira septentrionalis (Colubridae) after trying to ingest an individual of $R$. humboldti through its cloacal region. On the other hand, the inefficiency of this type of ingestion for some predators could induce the toad to display a type of behaviour different from the initial one or to display synergistic types of behaviour, as observed for individuals handled on the dorsum/dorsolateral which showed a higher frequency of defensive responses. Likewise, the absence of defensive responses could be related to the common strategies of foraging by predators. Generally, anuran predators are reported to capture their prey by headfirst ingestion, by the dorsum/ dorsolateral regions or by the posterior portion of the body, showing that it is not common for capture by the fore- and hind limbs (see Mori 2006). Therefore, the latter condition may be related to the lack of defensive responses in $R$. major when handled by the limbs. In our sampled areas, the possible gape-limited predators of $R$. major observed were the snakes Boa constrictor (Linnaeus 1758) and Helicops angulatus (Linnaeus 1758) and the lizard Tropidurus hispidus (Spix 1825) and additional maximised naturalistic observations about these predators can substantiate our predictions about the anti-predator behaviour of this toad.

Furthermore, we did not observe escape behaviour in $R$. major during our study. In fact, species of the genus Rhinella are relatively heavy and escape behaviour can be an inefficient alternative when it comes to highly mobile predators. Additionally, cryptic species may increase the likelihood of being detected if they escape (Cooper Jr et al. 2008). Therefore, the relative absence of use of the escape behaviour in anurans could be related to species with a high defensive repertoire, with active and passive defences, as reported for the species in our study and in informal reports (e.g. Pedroso-Santos et al. 2018, 2020).

As a final comment, although cryptic patterns were not the focus of this study, we reiterate that further studies are needed to evaluate the importance of selective pressure on phenotypic divergence amongst populations of $R$. major. This species, like the others in the group, can confuse predators guided only by vision because the dorsal cryptic pattern is similar to the complex background of its habitats. Therefore, our observations may support investigations of this nature. In addition, we encourage the necessity of experimental studies involving video traps to better evaluate the importance of defensive responses for prey detection and avoidance learning can be evaluated for different predator taxa. 


\section{Acknowledgements}

We are grateful to Daniela C. Rößler for proofreading and for valuable comments on the earlier draft of the manuscript and the two anonymous reviewers who kindly reviewed and provided cordial criticisms to our work. FPS received a fellowship from Conselho Nacional de Desenvolvimento Científico e Tecnológico (CNPq) during this study (process 134760/2018-2).

\section{References}

Alvares CA, Stape JL, Sentelhas PC, Gonçalves JLM, Sparovek G (2013) Köppen's climate classification map for Brazil. Meteorologische Zeitschrift 22: 711-728. https://doi.org/10.1127/0941-2948/2013/0507 Brodie Jr ED, Formanowicz DR, Brodie III ED (1991) Predator avoidance and antipredator mechanisms: distinct pathways to survival. Ethology Ecology \& Evolution 3: 73-77. https://doi.org/10.1080/08 927014.1991.9525390

Cassill DL, Vo K, Becker B (2008) Young fire ant workers feign death and survive aggressive neighbors. Naturwissenschaften 95: 617-624. https://doi.org/10.1007/s00114-008-0362-3

Cooper Jr WE, Caldwell JP, Vitt LJ (2008) Escape responses of cryptic frogs (Anura: Brachycephalidae: Craugastor) to simulated terrestrial and aerial predators. Behaviour 145: 25-38. https://doi. org/10.1163/156853908782687250

Duellman WE, Trueb L (1994) Biology of amphibians. $2^{\text {nd }}$ edn. John Hopkins University, Baltimore, 696 pp.

Escobar-Lasso S, González-Duran GA (2012) Strategies employed by three Neotropical frogs (Amphibia: Anura) to avoid predation. Herpetology Notes 5: 79-84.

Figueiredo-de-Andrade CA, Silveira LS (2018) The defensive behaviour of Rhinella pygmaea (Myers \& Carvalho, 1952) (Anura: Bufonidae). Herpetology Notes 11: 205-207.

Frost DR (2021) Amphibian Species of the World: An Online Reference. Version 6.0. http://research.amnh.org/herpetology/amphibia/ index.html [Last accessed on 10 March 2021] [American Museum of Natural History, New York]

Fonseca MG, Silva AN, Freitas TR, Vieira RB, Maffei F (2018) Predation of Rhinella granulosa by another bufonid, Rhinella jimi (Amphibia: Bufonidae) in Northeastern Brazil. Herpetologia Brasileira 7: 72-74.

Ferreira RB, Lourenço-de-Moraes R, Zocca C, Duca C, Beard KH (2019) Antipredator mechanisms of post-metamorphic anurans: a global database and classification system. Behavioral Ecology and Sociobiology 2019: 1-21. https://doi.org/10.1007/s00265-019-2680-1

Humphreys RK, Ruxton GD (2018) A review of thanatosis (death feigning) as an anti-predator behavior. Behavioral Ecology and Sociobiology 2018: 1-16. https://doi.org/10.1007/s00265-017-2436-8

Mângia S, Santana DJ (2013) Defensive behavior in Rhinella granulosa (Spix, 1824) (Amphibia: Anura: Bufonidae). Herpetology Notes 6: 45-46.

Miyatake T, Nakayama S, Nishi Y, Nakajima S (2009) Tonically immobilised selfish prey can survive by sacrificing others. Proceedings of the Royal Society B 276: 2763-2767. https://oi.org/10.1098/ rspb.2009.0558
Miyatake T, Katayama K, Takeda Y, Nakashima A, Sugita A, Mizumoto M (2004) Is death-feigning adaptive? Heritable variation in fitness difference of death-feigning behaviour. Proceedings of the Royal Society B 271: 2293-2296. https://doi.org/10.1098/rspb.2004.2858

Morri A (2006) Is headfirst ingestion essential in gape-limited predators? Prey-handling behavior of the anurophagous snake Rhabdophis tigrinus (Colubridae). Canadian Journal of Zoology 84: 954-963. https://doi.org/10.1139/z06-073

Narvaes P, Rodrigues MT (2009) Taxonomic revision of Rhinella granulosa species group (Amphibia, Anura, Bufonidae), with a description of a new species. Arquivos de Zoologia 40(1): 1-73. https://doi. org/10.11606/issn.2176-7793.v40i1p1-73

Pereyra MO, Blotto BL, Baldo D, Chaparro JC, Ron SR, Elias-Costa AJ, Iglesias PP, Venegas PJ, Thomé MTC, Ospina-Sarria JJ, Maciel NM, Rada M, Kolenc F, Borteiro C, Rivera-Correa M, Rojas-Runjaic FJM, Moravec J, De la Riva I, Wheeler WC, Castroviejo-Fisher S, Grant T, Haddad CFB, Faivovich J (2021) Evolution in the genus Rhinella: a total evidence phylogenetic analysis of neotropical true toads (Anura: Bufonidae). Bulletin of the American Museum of Natural History 447: 1-156. https://doi.org/10.1206/00030090.447.1.1

Pedroso-Santos F, Abi-Rezik P, Sanches PR, Costa-Campos CE (2020) Rhinella major (Müller \& Hellmich, 1936) and Rhinella gr. margaritifera (Laurenti, 1768) as unusual food sources for spiders. Alytes 37: 47-52.

Pedroso-Santos F, Sanches PR, Sousa JC, Costa-Campos CE (2018) Natural History Notes. Rhinella major (Granulated toad). Predation. Herpetological Review 49: 309-310.

Pyron RA, Wiens JJ (2011) A large-scale phylogeny of Amphibia including over 2800 species, and a revised classification of extant frogs, salamanders, and caecilians. Molecular Phylogenetics and Evolution 61: 543-583. https://doi.org/10.1016/j.ympev.2011.06.012

Sazima I (1978) Convergent defensive behavior of two leaf-litter frogs of southeastern Brazil. Biotropica 10: 158-158. https://doi. org/10.2307/2388020

Toledo LF, Ribeiro RS, Haddad CFB (2007) Anurans as prey: an exploratory analysis and size relationships between predators and their prey. Journal of Zoology 271: 170-177. https://doi.org/10.1111/ j.1469-7998.2006.00195.x

Toledo LF, Sazima I, Haddad CFB (2010) Is it all death feigning? Case in anurans. Journal of Natural History 44: 1979-1988. https://doi. org/10.1080/00222931003624804

Toledo LF, Sazima I, Haddad CFB (2011) Behavioural defences of anurans: an overview. Ethology Ecology \& Evolution 23: 1-25. https:// doi.org/10.1080/03949370.2010.534321

Valencia-Zuleta A, Tosta N, Maciel NM (2020) First account of Rhinella mirandaribeiroi (Anura: Bufonidae) as prey of the giant water bug Lethocerus annulipes (Hemiptera: Belostomatidae), with additional observations of predation on Physalaemus nattereri (Anura: Leptodactylidae). Herpetology Notes 13: 845-847.

Vargas-Salinas F, Aponte-Gutierrez A (2013) A race for survivorship: failed predation on the toad Rhinella humboldti (Gallardo, 1965) by the Cat-eyed snake Leptodeira septentrionalis (Kennicott, 1959). Herpetology Notes 6: 189-191.

Wells KD (2007) The Ecology and Behavior of Amphibians. University Chicago Press, Chicago, 1148 pp. 